\title{
Industrias del creer. Orientaciones productivas del complejo editorial cristiano en Argentina*
}

\author{
JOAQUÍN ALGRANTI
}

El objetivo del artículo es estudiar las industrias culturales religiosas y la producción de objetos espiritualmente marcados. Para ello llevamos adelante una investigación de las principales editoriales católicas y evangélicas de Argentina que comercializan fundamentalmente libros, películas y música. Nos concentraremos entonces en el análisis de las orientaciones productivas, los perfiles de consumidores-creyentes y las marcas religiosas de sus productos culturales.

PALABRAS CLAVE: cultura material, mercancías religiosas, editoriales, católicos, evangélicos

Believe Industries. Productive Orientations of the Christian Publishing Houses in Argentina

The aim of this paper is to study the cultural religious industries and the production of spiritually marked objects. We conducted a research of the main catholic and evangelical publishing houses in Argentina, which commercialize mostly books, movies and music. We will focus in the analysis of the productive orientations, the consumer-believer's profiles and the religious marks of their cultural products.

KEYwORDS: material culture, religious goods, publishing houses, Catholics, evangelicals 


\title{
Introducción
}

\author{
Olvidémonos de la idea de la irracionalidad del \\ consumidor. Olvidémonos de que las mercancías \\ sirven para comer, vestirse y protegerse. Olvidemos \\ su utilidad e intentemos en cambio adoptar la idea \\ de que las mercancías sirven para pensar (Douglas \\ e Isherwood, 1990: 77).
}

$\mathrm{n}$ términos generales, las religiones no son nunca un conjunto atomizado de narrativas, símbolos e imágenes, desconectadas entre sí. Existen principios de orden que integran y en el mismo acto dotan de identidad a la aparente dispersión de las referencias espirituales. Poseen, por ejemplo, un ordenamiento práctico de ideas con base en ritos más o menos instituidos, así como un sustrato material que las refuerza y las organiza en un mundo de objetos grabados. No es la religión a solas, sino la religión y sus “cosas": estampitas, manuales, libros y películas, agendas, ropas rituales, cadenitas y distintivos. Son los objetos y sus marcas los que componen los signos de una determinada cultura material de la vida religiosa. Los elementos que nos ocupan en este artículo son un tipo específico de mercancía y de empresa u organización económica. Se trata, en ambos casos, de realidades híbridas en las que se conjugan — a veces se retroalimentan con base en adecuaciones y analogías, y otras en franco antagonismo- legalidades diferentes expresadas en el cosmos económico y el religioso. Nuestra investigación se enfoca en el "pequeño gran" mundo de los productores de bienes culturales. Nos interesa aquí, por ser la rama con mayor historia y desarrollo, el complejo dominio de la producción editorial, vale decir el libro fundamentalmente cristiano y sus variantes - católicas y evangélicas-, sin abandonar pretensiones comparativas con editoriales judías y otras concentradas en grupos religiosos de raigambre oriental.

El espacio de producción de mercancías religiosas representa un terreno más vasto que el circuito estricto del medio editorial. En este sentido, y si nos concentramos casi exclusivamente en la literatura latinoamericana, reconoceremos que dentro de 
la sociología y la antropología de la religión existe un corpus $^{1}$ de estudios sobre aspectos de la producción cultural religiosa. La ponderación de los fundamentos teóricos de este corpus y sus líneas de estudio excede los límites del apartado. Para los fines del artículo basta con justificar la elección de nuestro objeto por el alto grado de industrialización y diversificación que presenta el complejo editorial en comparación con otras industrias culturales religiosas, a excepción tal vez de las santerías. Es importante señalar que las editoriales se distinguen por historia y procedencia en dos modelos productivos: uno como prolongación de organizaciones religiosas y otro como decisión de emprendedores privados que inician un negocio familiar. Nuestro trabajo de campo tiene como objetivo, en primer lugar, reconstruir el sistema de clasificación que aplican los entrevistados a la hora de ubicar su propia empresa y las tareas que los convocan en relación con las otras. Se trata de un espacio de referencia regido por dos vectores dominantes: uno que denominaremos "espiritual" y otro "comercial". A continuación nos proponemos reconocer los perfiles de consumidores-creyentes hacia los que se orientan los bienes culturales que fabrican, distribuyen y venden las editoriales. Por último, plantearemos el problema de las marcaciones religiosas, fuertes y débiles, que le otorgan identidad a los productos en cuestión.

El artículo presenta los resultados de un proyecto de investigación en torno a los circuitos de producción y distribución de las editoriales religiosas en la ciudad de Buenos Aires, Argentina. El trabajo de campo comenzó a principios de 2009 en el marco institucional del Consejo Nacional de Investigaciones Científicas y Técnicas (Conicet). En un inicio incluyó entrevistas en profundidad, registros y lecturas de documentos de las siguientes editoriales católicas y evangélicas: San Pablo, Paulinas, Bonum, Agape, Peniel y Kairós. El criterio de elección de las empresas tuvo como objetivo diferenciar las unidades productivas de acuerdo con su pertenencia a estructuras religiosas - congregaciones, templos, fundaciones, etc. - o laicas — sociedades anónimas-. Se entrevistó en particular a directores, encargados de áreas o departamentos y en menor medida a vendedores y autores cristianos vinculados a estos sellos. El segundo momento comenzó a fines de 2010 y se extiende hasta 2013 a partir del proyecto PICT 2010-0524, "Espacio de producción cultural y religión en Buenos Aires. Análisis comparado de las estrategias de producción y circulación de bienes simbólicos en el mundo evangélico", financiado por la Agencia Nacional de Promoción Científica y Tecnológica. En esa instancia se incorporaron nuevas editoriales católicas, como Guadalupe, evangélicas, como los Hermanos Libres, y editoriales de otros grupos religiosos, como Kehot y Deva's para el mundo judío y las formas alternativas de espiritualidad, respectivamente. A su vez, se llevó a cabo observación participante de eventos editoriales, actividades de difusión, campañas evangélicas, seminarios y cursos especializados para estudiar el régimen de circulación de los objetos religiosos.

\section{¿Quién es quién? Orientaciones productivas del mundo editorial}

El espacio editorial es un territorio atravesado, en primera instancia, por dos coordenadas de referencia que permiten situar a los agentes productores y comprender sus apuestas, cálculos, riesgos, expectativas y ganancias. Las dos orientaciones dominantes pueden ser

1 Es el caso de Lewgoy (2004), Silveira (2012), Semán (2006) y Ludueña (2009) en lo que respecta a producción y consumo de literatura cristiana y espirita. Sobre música evangélica y medios de comunicación están Garma (2000), Meyer (2006) y Martinoff (2010). Los análisis de Belchior (2007) atienden la ética del consumo que acarrea la teología de la prosperidad y De la Torre (2006, 2008), De la Torre y Gutiérrez (2005), Wright y Messineo (2013) estudian la oferta neoesotérica. 
caracterizadas bajo los términos de vector espiritual y vector comercial. Mientras el primero designa una política de producción cultural que prioriza los acentos religiosos-doctrinales y se dirige a un circuito "restringido" de consumo - para utilizar la expresión de Pierre Bourdieu (2003: 90)—, el segundo se refiere a una orientación productiva que apunta al circuito "ampliado", al gran público, con base en materiales que subordinan los motivos religiosos a su faceta comercial. Toda casa editora lleva a cabo un proceso de síntesis y equilibrio dinámico entre ambas fuerzas. Elegimos, a falta de un mejor término, la noción preliminar de vector para dar razón de una idea de dirección, fuerza, rango y alcance del proceso productivo de bienes religiosos. No existe por tanto una empresa que encaje plenamente, palmo a palmo, en uno u otro de los extremos que describiremos, aunque algunas se acercan mucho en momentos específicos de su desarrollo.

La caracterización de cada vector corresponde a ciertos ejes comunes a partir de los cuales pudimos reconocer los vértices de este espacio de relaciones. Haremos blanco en: 1) el modelo organizativo; 2) la relación con la doctrina religiosa; 3) las áreas dominantes de producción; 4) las lógicas de financiamiento con sus redes comerciales; 5) la política de selección de autores; 6) los perfiles de consumidores con prioridad, y 7) el juego de articulaciones que se establecen con otras instituciones del medio. Se trata, como dijimos, de una caracterización general que parte de la empírea, pero que presentamos vaciada de rasgos particulares con el único objetivo de explicar los principios dominantes de estructuración que ordenan el pequeño cosmos de la vida editorial y sus procesos de entramado.

\section{"Nosotros tenemos lo que hace falta, que lo vengan a buscar"}

El vector espiritual muestra correspondencias con el modelo religioso de producción de libros, es decir, con aquellas empresas que surgen como extensión de las formas de sociabilidad de templos, sinagogas e iglesias (Algranti, 2011: 88-89). El vínculo es de correspondencia o analogía, no de causalidad mecánica entre uno y otro. Por eso el desafío consiste en encontrar el grado de adecuación entre elementos, habilitar la existencia de desfases según el periodo y el caso a estudiar. Por lo general, el modelo organizativo que mejor se ajusta a este vector es el de la asociación civil sin fines de lucro o la fundación ligada a congregaciones, asambleas o movimientos religiosos. Prima aquí la concepción de iglesia-empresa, bajo la retórica del visionario fundador — el padre Alberione, la hermana Tecla Merlo, el pastor Pablo Besson o el rebe Menajem Mendel Schneerson-. En términos morfológicos el rasgo distintivo de este modelo consiste en una conducción empresarial en manos de especialistas — curas, monjas, rabinos y pastores- con formación profesional en instituciones confesionales. También es preciso mencionar la incorporación paulatina de laicos como figura complementaria en la división interna del trabajo. Respecto de los matices doctrinales, el vector espiritual refuerza una idea de pureza basado en la importancia de la "Palabra", sus interpretaciones y acentos, sobre la noción de "experiencia" religiosa que habita el extremo opuesto, o sea, el vector comercial. El foco teológico vuelve recursivamente sobre la importancia de los textos sagrados y su construcción doctrinal en tanto cuerpo coherente de enseñanzas e instrucciones a cargo de clérigos que fijan límites. Para ciertas editoriales y temas del mundo judío un libro apropiado es el que cumple con los preceptos de kashrut, es decir, que es kósher. Lo mismo ocurre con el proceso de obtención del Nihil Obstat según los códigos del derecho canónico para publicar textos de catequesis y formación católica con las consecuentes sanciones que puede aplicar El Vaticano sobre materiales que trabajan temas sensibles por fuera de los lineamientos doctrinales. Este vector se presenta como guardián consagrado de la Palabra y sus interpretaciones, por eso las áreas dominantes, 


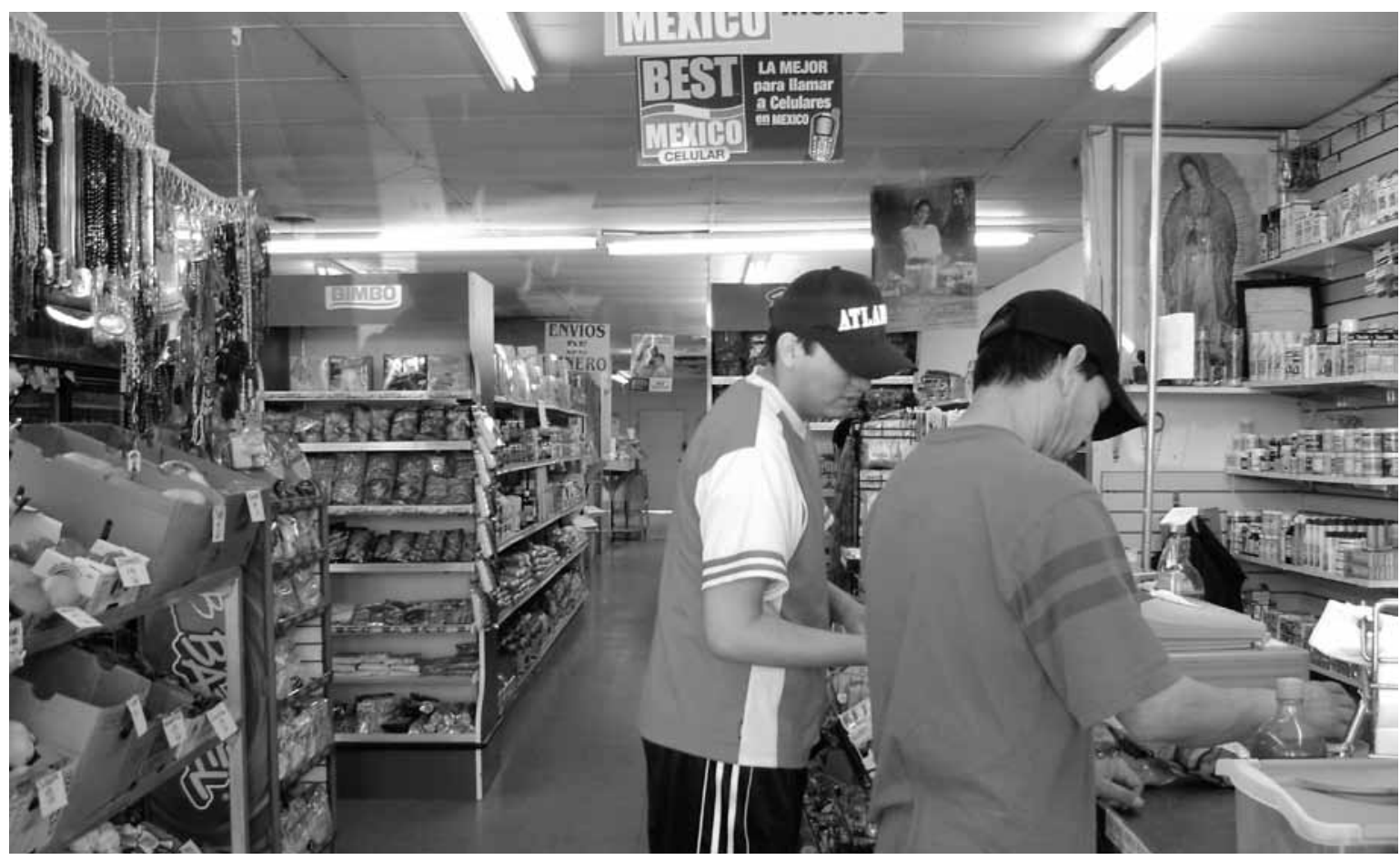

PATRICIA FoRTUnY Comercio dirigido a consumidores latinos y mexicanos en el que se exhibe el símbolo religioso/nacional de la Virgen de Guadalupe. Smyrna, Atlanta, Georgia, 2008.

aunque no exclusivas, de publicación obedecen a los materiales de liturgia, pastorales, formación religiosa, estudios bíblicos, diccionarios especializados, documentos, Biblias, libros de oraciones, educación, teología y sexualidad. Existe, naturalmente, una ampliación complementaria "hacia lo carismático", como señalan las entrevistas, pero no es la especialidad del vector espiritual, que mira de reojo y con cautela las formas religiosas centradas sólo en la experiencia. A su vez, como estas últimas, las relegadas, son las áreas de mayor éxito comercial, la lógica financiera del vector descansa en parte en un régimen de recursos confesionales que le permiten subsistir con base en una cultura de donación y mecenazgo. La organización misionera Society for Promoting Christian Knowledge (SPCK), fundada en 1698 por anglicanos, y la evangélica World Vision (wv), creada en 1950, son ejemplos puntuales que emergen de nuestras entrevistas de agencias externas que ofician de mecenas, vale decir, financian, capacitan y becan proyectos editoriales del circuito protestante. Asimismo, la cultura de la donación representa una de las principales pautas financieras y simbólicas que rige la vida editorial de Kehot Lubavitch dentro del movimiento jasídico, a partir de los aportes privados de familias que solventan ediciones y son reconocidas por los miembros de la comunidad de Jabad. Otro de los ejes fundamentales es la ampliación de las redes productivas que ofrecen las cadenas de interdependencia religiosas, que se traducen en ventajas competitivas a la hora de editar, imprimir y poner en circulación los materiales del caso. También suponen espacios internacionales de capacitación y circulación en los que pueden adoptarse políticas conjuntas para reducir costos. La Red Letra Viva del circuito cristiano-evangélico o 
el Servicio Apostólico Latinoamericano del cual participa la editorial católica Paulinas son ejemplos de organizaciones de gran escala que fijan estrategias globales de comercialización. Las redes religiosas, en todo su alcance y espesor, otorgan a este vértice cierta independencia respecto del mercado y habilitan la especialización en la pureza de la doctrina. De acuerdo con este recorte, el sentido dominante en materia de selección y promoción de autores apunta a fomentar el surgimiento de escritores locales, del medio, por sobre el trabajo de traducción de grandes figuras internacionales. Es la lógica del "semillero", de los libros por pedido, que conserva —en algunos sectores de este vector, no en todos - una presencia interesante vinculada a la política de creación ex nihilo de figuras desconocidas para el mundo editorial. A la hora de clasificar la oferta nos encontramos con una orientación comercial que prioriza las necesidades de especialistas y creyentes formados o en formación. Son bienes culturales dirigidos, en primer lugar, hacia lo que denominaremos el núcleo duro y los cuadros medios de las variantes del mundo religioso. Apuntan a un modelo de consumidor ya iniciado, instruido en las formas de la vida espiritual, que busca - siempre en la representación que hacen los productores de sus destinatarios- aprender una técnica, capacitarse intelectualmente, explorar nuevos sentidos o profundizar los que ya conoce. Este vector tiende a relegar al creyente lego o desentendido, que habita de diferentes modos la periferia de las instituciones, y también a las posiciones marginales ajenas por completo a su universo de creencias. Si exageramos el argumento podemos decir que ofrecen bienes culturales hechos por religiosos para religiosos. El grueso de los feligreses o seguidores ocupa un lugar secundario, son - para usar una expresión entre burlona y despectiva que circula en el medio evangélico- la "creyentada". No es extraño entonces que esta corriente de producción cultural tienda a construir articulaciones duraderas con instituciones educativas, escuelas, universidades, institutos, seminarios de formación, cursos de catequesis, etc. Existe un principio activo de afinidad entre los objetos culturales que se fabrican por oficio y trayectoria bajo esta orientación y los materiales que suelen demandar las instituciones profesionalmente abocadas a la celebración de cultos, la enseñanza y la trasmisión de un legado religioso. Subyace, al menos en potencia, la concepción modernista de la vanguardia que clasifica y distingue entre la alta y la baja cultura, la elite y la masa, los pastores y la "creyentada". Su lema —en palabras de Jorge, uno de nuestros primeros informantes clave - es: "Nosotros tenemos lo que hace falta, que lo vengan a buscar".

\section{Traer lo que funciona}

Para comprender el espacio de producción de mercancías religiosas debemos reconstruir una segunda corriente que direcciona el trabajo de las editoriales: el vector comercial. Desde la óptica desarrollada más arriba éste es el dominio de "lo carismático", "la venta", "el supermercadismo", es decir, un espacio gobernado por la primacía de los criterios económicos y mundanos sobre los criterios religiosos. Retomemos los ejes que trabajamos en el último párrafo. El modelo organizativo que tiende a imponerse aquí es el de la empresa familiar bajo la figura de la sociedad anónima en la que la participación en el negocio supone una expectativa de ganancia una vez cubierta la reproducción simple y ampliada de los capitales invertidos. La visión de empresa se alimenta de la retórica del emprendedor o el misionero laico, un self made man que decide evangelizar a través de su obra y al mismo tiempo o después sus familiares la perpetúan. Es importante destacar que la dimensión del lucro implica un grado de impureza, pero no se desprende del hecho de orientar la producción hacia las fórmulas de éxito que se ajustan a la demanda del gran público. Desde la perspectiva sacerdotal que conduce el otro vector, 
el carácter impuro tiene que ver con que estas fórmulas cambian el eje de la doctrina y relegan la $\mathrm{Pa}-$ labra, el estudio bíblico, con sus matices, acentos y astucias interpretativas en función de la experiencia de lo sagrado narrada a través de testimonios singulares. El elemento vivencial y el sentido de la fe pasa a ser el tema por excelencia de la corriente comercial. Es el discurso interno (Volóshinov, 2009: 30-35) de una persona que narra las circunstancias, aventuras y desventuras de su vida interior en el proceso de encuentro con alguna forma de divinidad, con el agregado de que el género testimonial —en sus variantes católica, evangélica, judía o alternativa- habilita perfiles de autor ajenos a las posiciones nucleares, es decir, al cuerpo de sacerdotes. La orientación económica hacia un mercado amplio de producción cultural habla el lenguaje del best seller y en el mundo religioso éste es indisociable de la experiencia de Dios en todas sus formas. Por eso las áreas dominantes versan sobre espiritualidad, testimonios y biografías, devocionales, vidas de santos, autoayuda, motivación, sanidad, liderazgo y vida práctica, entre otras. Comparten el "sentimiento de presencia”, en términos de William James (1994: 51-55), de las verdades cálidas propias de una religión del corazón. ${ }^{2}$ La diversificación productiva los lleva también a incorporar de manera complementaria materiales de estudio dedicados a la exégesis y la hermenéutica de las Sagradas Escrituras. En materia de financiamiento este vector depende por completo del éxito comercial, no hay recursos de iglesias, federaciones o agencias internacionales. Aquí no juegan las redes espesas del complejo religioso ni la cultura del mecenazgo o la donación. De ahí que la política editorial opere bajo la premisa de "traer lo que funciona", apostar fuerte a la importación y promover la venta de franquicias - como es el caso de Peniel, Deva's o Agape- una vez que la empresa se posiciona en el mercado. Este vector se interesa, en principio, en traducir e instalar a autores extranjeros sin descartar la promoción de referentes locales ligados, por ejemplo, a mega iglesias evangélicas — pastor Mrai$\mathrm{da}$-, movimientos carismáticos — padre Jamut-o celebridades del mundo del espectáculo - Ari Paluch-. Aunque no existe un grado suficiente de integración y diversificación institucional que justifique hablar de un star system - para utilizar el término clásico de Edgar Morin (1964: 9-10)— de la industria religiosa, las grandes editoriales - Peniel es un caso ejemplar- construyen sus perfiles públicos con base en autores emblemáticos que se convierten en la cara más visible y representativa de su sello. A su vez, la política de traducción promueve la búsqueda de acuerdos comerciales con grandes editoras o grupos económicos - grupo Zondervan o editorial Herder, por ejemplo- a través de los cuales se conforman redes ampliadas de producción y sobre todo de circulación en el mercado de habla hispana compuesto por América Latina, parte de Estados Unidos y España. Es evidente que el perfil dominante al que apunta esta orientación es el gran público, la "creyentada", los fieles que habitan la periferia e incluso los márgenes de las instituciones religiosas. Pese a que la espiritualidad también es un consumo de las posiciones nucleares e intermedias, logra mayor alcance y aceptación entre los legos porque muchas veces se trata de un discurso hecho por periféricos para periféricos o para personas ajenas al culto. En términos de articulaciones institucionales, la corriente comercial trabaja en gran parte con iglesias grandes y medianas, con federaciones y eventos convocantes - ferias, actos, encuentros y campañas- en los que pueda colocar a autores conocidos o por conocer. Aquí sobresalen los evangélicos, incluso a los ojos de otras confesiones, en la tarea de difundir su cultura material en los espacios situados de celebración y encuentro. En algunas versiones de esta

2

Para un estudio sobre la industria cultural, la vida cotidiana y el discurso de autoayuda en Argentina véase el artículo de Canavire (2013). 


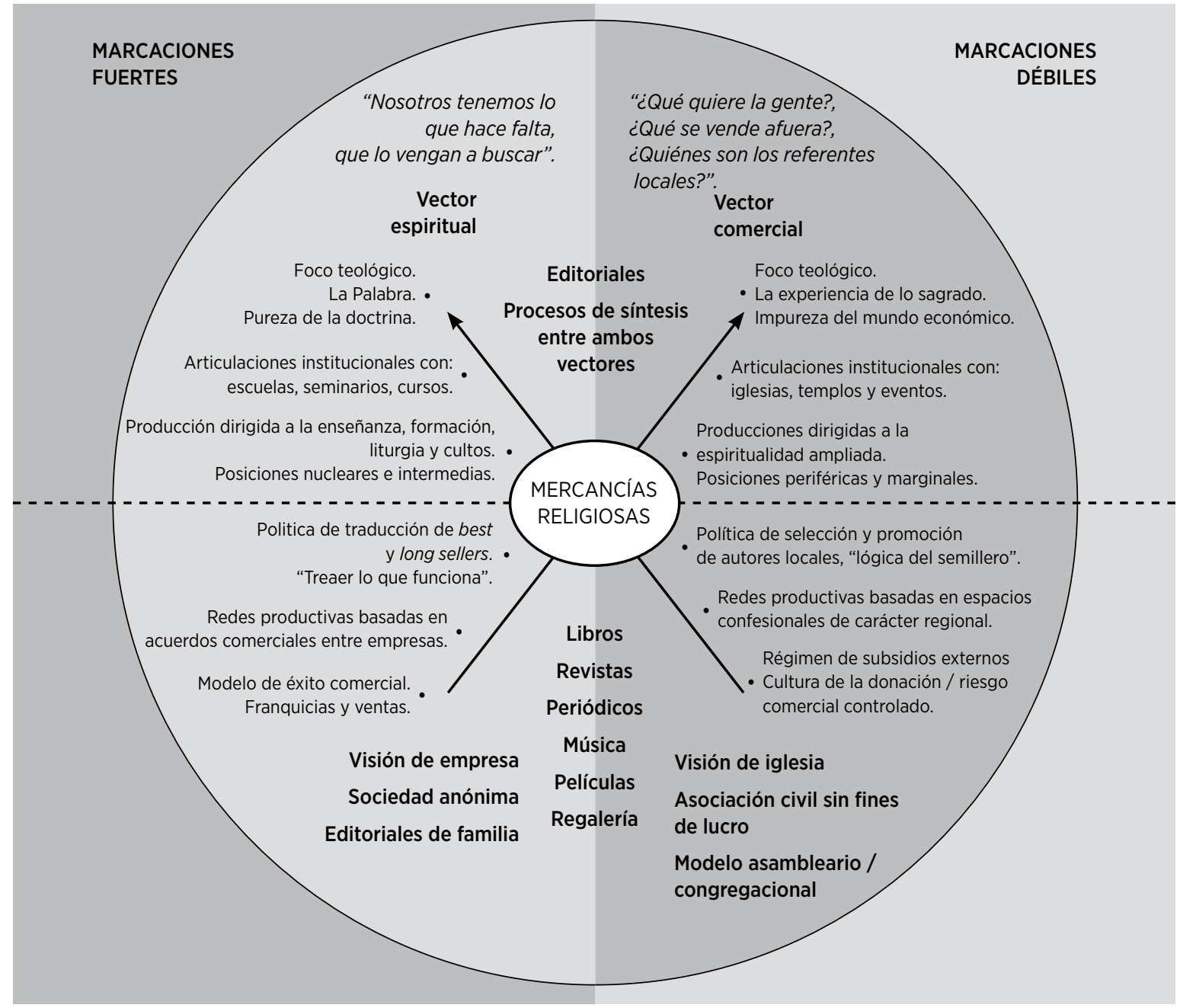

Fuente: Elaboración propia con base en trabajo de campo (2009-2013).

orientación impera un concepto muy colonizado y colonizante de la producción cultural, en el que la casa editora aparece como un satélite de grandes empresas o instituciones extranjeras que definen la forma y el contenido de los productos. Los modos del imperialismo editorial pueden obedecer tanto a las exigencias del mercado y la lógica del best seller como al control estricto de los contenidos religiosos por parte de instituciones extranjeras que monitorean la producción local. La idea de Miami como capital cultural de América Latina, trabajada por George Yúdice (2008: 239-250), bien puede aplicarse a un sector importante del mundo evangélico que encuentra en esta región un polo de producción de libros y todo tipo de contenidos cristianos. En todo caso y más allá de las diferencias, las preguntas que rigen a este vector son: ¿qué quiere leer la gente?, ¿qué se vende afuera? y ¿a quién siguen? 
Podemos reunir los vectores señalados en un gráfico que, pese a simplificar el argumento esgrimido, nos permite componer de un vistazo las líneas rectoras de nuestro análisis sobre las mercancías religiosas. Se propone un modo de lectura no sólo en la dirección que marcan las flechas, sino también vertical, por mitades, como sugieren los tonos, para indicar que una visión de empresa o de iglesia puede redireccionarse en cualquier momento hacia una orientación diferente a su origen. Recordemos una vez más que el valor heurístico que pueda tener este sistema de clasificación subterráneo depende del análisis de las casas editoriales en tanto síntesis de ambos tipos de orientaciones hacia lo espiritual y hacia lo comercial. En la historia interna de algunas empresas puede primar un vector y luego su crecimiento o llega a suceder que una crisis las obliga a redefinir sus políticas e imponer el otro. Por eso son orientaciones o coordenadas las que nos permiten saber quién es quién en el espacio de producción de libros religiosos en la medida en que comprendamos analíticamente no sólo la estructura estática, el presente de una organización, sino también su génesis y su dinámica en el tiempo. Ambos vectores inciden hacia adentro en la reproducción e innovación de sus materiales. Conjugan una oferta cultural que incluye en diferente medida e intensidad las posiciones clásicas de la sociología weberiana de la religión, es decir, las figuras rivales pero complementarias del sacerdote, el profeta y el hechicero. Podemos decir que tanto la tarea sacerdotal de custodiar y trasmitir lo sagrado en su liturgia, catequesis y devocionales como la acción herética que subvierte las formas dominantes bajo el discurso puro del retorno a las fuentes y el despliegue de estrategias cercanas a la magia que satisfacen necesidades prácticas y concretas — sanidad, liderazgo, depresiones, éxito laboral, bienestar etc. - forman parte de los bienes de cultura que ponen a disposición las casas editoriales al tratar de escribir el mundo. El modo en el que lleven adelante esta operación depende de los principios de orden que privilegien en un momento determinado.

\section{La "creyentada" y otros perfiles de consumidores}

Las dos coordenadas del circuito editorial se conjugan con una caracterización posible de los perfiles de consumidores-creyentes, que surge sobre todo de las entrevistas a directivos evangélicos y de estudios contemporáneos. ${ }^{3}$ Esta caracterización tiende a clasificar al mercado en homología con las formas de pertenencia a las instituciones cristianas al distinguir entre los profesionales de la religión y sus aspirantes, es decir, el cuerpo sacerdotal de pastores, curas, seminaristas y religiosos, los miembros del laicado comprometidos parcial o totalmente con las organizaciones, la enorme zona indefinida de creyentes que se identifican tal vez con una creencia en particular, pero se alejan de sus dogmas e incursionan en numerosas formas de espiritualidad en paralelo, y por último las personas de otros credos o del mismo que las editoriales que se encuentran alejadas y a las que se pretende llegar con una oferta cultural específica. Recordemos que estas formas sociales de etiquetamiento corresponden, al menos en primera instancia, a los esquemas de percepción de los productores de bienes simbólicos, preocupados por ordenar la dispersión del medio a través de diferenciaciones segmentadas del público:

Dentro de la comunidad evangélica hay cierto tipo de públicos. Están los que son líderes dentro de una iglesia local, gente que trabaja con niños, con jóvenes, con adolescentes, que tiene su grupo pequeño.

3

Según el análisis estadístico de Catoggio, Irrazábal y López (2013: 180-188) en torno a las prácticas y creencias religiosas relacionadas con la asistencia al culto, es interesante señalar que los hábitos culturales vinculados a la lectura de la Biblia, libros o folletos religiosos, así como el consumo de programas de las mismas características en radio y televisión, crecen en los perfiles de creyentes que asisten con más frecuencia a templos e iglesias. Pareciera que el consumo de ciertos objetos culturales se potencia por las formas de sociabilidad religiosa ligadas a la experiencia institucional de cultos y misas. 
Que vos sabés que el tipo necesita tal tipo de libro. Después están los pastores que por ahí tienen otra perspectiva, otras necesidades, algunas son similares y otras no. Y después está lo que es el grupo de creyentes más generalizados que te consume libros de vida cristiana, de autoayuda evangélica, el perdón y cosas así, libros más testimoniales. Es la “creyentada", es la gente que más rota. Podés identificar a un público dentro del grupo general que son los jóvenes, entonces, van a tener toda una serie de libros sobre noviazgo, sexo, drogas, sexualidad, toda la parte de música (Mariano, comisión directiva, Certeza Argentina).

Es posible renombrar dichos perfiles a partir de cuatro posiciones de sujeto complementarias: el núcleo duro, los cuadros medios, la periferia y los sectores marginales (Setton y Algranti, 2009), comprendidos en sí mismos en tanto perfiles potenciales de consumidores que ofrecen un criterio de orden del mercado. Si pensamos en un conjunto de elecciones culturales sostenidas en el tiempo e introyectadas en formas de hacer, pensar, sentir y mostrar la vida religiosa, nos encontramos con estilos nucleares o periféricos - por mencionar dos extremos- que moldean la identidad de los creyentes y el modo de relacionarse con su entorno, plantean una estética definida, una manera sensible de percibir lo "sagrado" con base en identificaciones de consumo. Las editoriales prefiguran en su oferta la existencia de estilos más o menos segmentados.

En este sentido, el núcleo duro, compuesto por los profesionales de la fe formados y en formación, cuenta con materiales específicos dirigidos justamente al sostén y aprendizaje de la liturgia, la catequesis, la difusión de documentos de la Iglesia y estudios teológicos y el trabajo con distintas áreas de la parroquia. También las posiciones nucleares del Evangelio son en sí mismas objetos de una oferta cultural específica que incluye las ayudas pastorales, la consejería, el crecimiento de la Iglesia, el trabajo de discipulado y creación de grupos pequeños, la predicación y el afianzamiento institucional entre sus temas principales. Es así que libros, música y películas son los tres registros que se combinan para dar respuesta a las necesidades prácticas del cuerpo nuclear de sacerdotes y pastores. Los cuadros medios de laicos activos conforman otro dominio más o menos diferenciado del mercado de bienes religiosos. El universo de coordinadores y catequistas puede constituirse como un perfil de potenciales consumidores interesados en libros sobre oración, familia, juventud, educación sexual y vida pastoral, según los rubros de las editoriales. Lo mismo pero con diferentes acentos ocurre con los líderes de célula: los Timoteos, Ujieres y demás posiciones de participación evangélica que cuentan con materiales de formación en las áreas que los involucran —discipulado, liderazgo juvenil, predicación, motivación, sanidad y crecimiento espiritual- Ninguna de estas posiciones son en principio excluyentes entre sí, sino que se refieren a un criterio de clasificación que asocia o articula el consumo con la práctica.

Entonces podemos reconocer un tercer grupo imaginario que identificamos con los miembros periféricos de toda religión: la "creyentada" para los evangélicos o los “católicos a mi manera”, como reconoce conceptualmente Fortunato Mallimaci (2009: 21) al mencionar el cuentapropismo religioso. Aquí los consumos representativos obedecen a temáticas vinculadas sobre todo con la espiritualidad, la autoayuda, la vida de santos, las biografías y en especial autores heterodoxos devenidos en best sellers, que establecen diálogos con otros campos del conocimiento, como Ansel Grüm con la psicología, Anthony de Mello con el mundo oriental y el budismo, o Bernardo Stamateas con el discurso de la autoayuda. La periferia es construida en parte por los productores de bienes culturales para delimitar al gran público en el mercado de consumo religioso. Lejos de constituir un bloque compacto y 


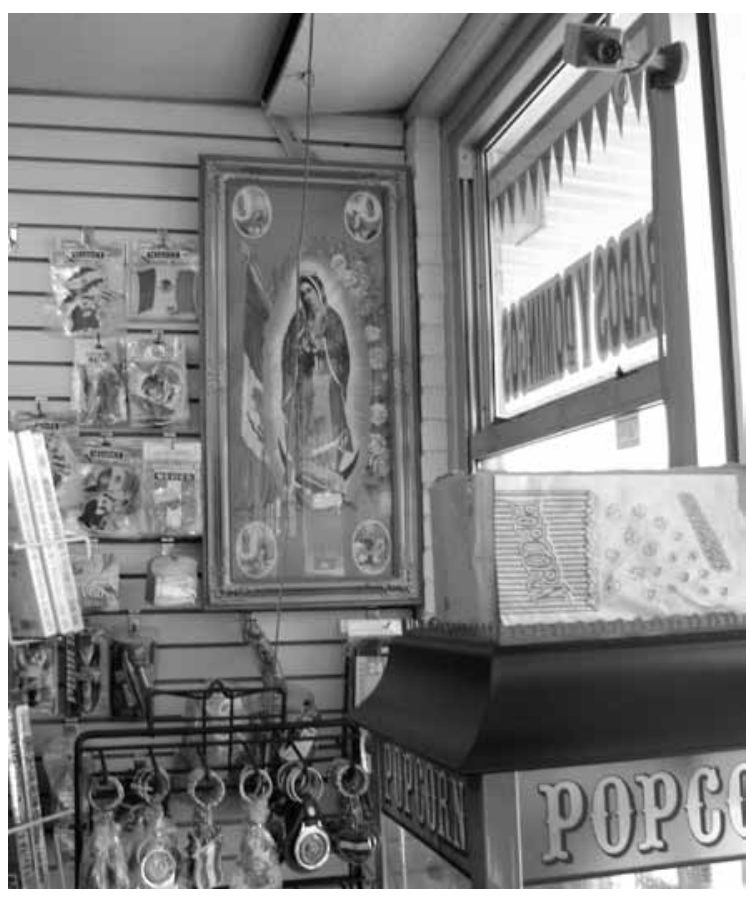

Patricia Fortuny - Comercio que exhibe el símbolo religioso de la Virgen de Guadalupe, Smyrna, Atlanta, Georgia, 2008.

homogéneo esta zona presenta numerosos matices dentro de las áreas mencionadas, sobre los cuales no podemos extendernos aquí. Sí nos interesa reconocer una distinción que estructura los consumos periféricos entre los productos dirigidos a los nuevos, los "recién llegados" al Evangelio, y los que apuntan, por el contrario, a un perfil de creyente más distante, ocasional y en continua circulación. Por último, nos encontramos con las posiciones "marginales", es decir, los perfiles de consumidores ajenos al credo que profesa la editorial, pero que también son un blanco de interpelación desde la literatura, la música y los DVDs dirigidos en particular a un trabajo activo de proselitismo. Existe una abundante literatura en el espacio evangélico orientada a aquellas personas del "mundo" que no conocen a Dios o que lo conocen de otra forma. Autores nacidos en los circuitos religiosos y consagrados en el circuito secular — la colección de Stamateas es el ejemplo paradigmático - representan un modo de alcanzar a las posiciones marginales, aunque no exclusivamente a ellas, con un discurso mixto a medio camino entre la espiritualidad y la autoayuda. En el fondo, lo que se pone en juego es el problema de las marcaciones religiosas de los bienes culturales orientados a ampliar o restringir las posibilidades efectivas de recepción.

\section{Cuestiones de marcación: señales fuertes y débiles}

Los objetos culturales son objetos marcados. Las marcaciones son un conjunto visible de referencias que permiten inscribir los bienes en un proceso comunicativo más amplio, una tradición, un diálogo, un debate de largo alcance o una controversia situada. Este proceso comunicativo los antecede en el tiempo y a su vez los trasciende, sin importar la intención de cierre o — podríamos decir- de sutura que los objetos reclamen para sí. Ellos representan una suerte de lenguaje, un sistema de comunicación en movimiento (Douglas e Isherwood, 1990: 87-92) con su modo sugerido de uso y su estructura implícita. Aquí se actualiza un código cifrado muchas veces para personas ajenas a ese universo de referencias, mientras que para otras el mismo código traduce un guiño o una forma secreta de complicidad. En cualquier caso, las marcaciones suponen esquemas de percepción definidos que delimitan un rango posible de consumidores apropiados para un bien cultural. Cuando se trata de mercancías - basadas en la reproductibilidad, el esquematismo y cierta estandarización formal- el lenguaje de las marcas corre el riesgo de caer en las figuras predecibles del estereotipo y el cliché, oportunamente anticipadas por la teoría crítica. Las marcas fuertes, en el sentido en el que lo utilizamos aquí, proponen una identidad restringida de los objetos, es decir, una definición específica construida a partir de 
exclusiones y diferencias irrevocables en la composición del producto. Por su parte, las marcas débiles apelan a una identidad ciertamente más amplia, incluso genérica, que refuerza la idea de un bien cultural a medio camino - o punto de intersección- entre varios universos simbólicos. Sin dejar de existir, las connotaciones singulares inscriptas en los bienes ceden terreno a marcas más amplias y polifónicas. Marcaciones fuertes y débiles estabilizan un tejido de sentidos que vuelven inteligibles el objeto cultural en cuestión. Veamos cómo operan en el circuito editorial.

En el mundo de la producción de libros religiosos existen tipos de marcaciones. Algunas son externas, como el diseño y la imagen de la tapa, el título, el nombre y la foto de los autores - a veces solos, otras con su esposa e hijos-, las referencias a otros libros exitosos del mismo autor, el texto de la contraportada, el de las solapas - con un breve currículum y la relación con otros libros de la misma colección-, fragmentos de recomendaciones de personas especializadas del medio - periodistas, curas, pastores, teólogos, personalidades de la cultura, etc.- - el logo de la editorial, el nombre de la colección y una anticipación, en algunos casos, de la persona que escribe el prólogo o el estudio preliminar que acompaña al texto. Las marcaciones externas constituyen en sí mismas un espacio de referencia que ubica el libro en un área específica de la vida religiosa. Si tomamos como ejemplo a las editoriales católicas y evangélicas las áreas pueden ser vida pastoral, liturgia, catequesis, Biblias, vidas de Santos, espiritualidad, liderazgo y negocios, consejería, devocional, discipulado, motivación, sanidad interior, autoayuda y la lista sigue. Las marcaciones dominantes de la tapa apuntan por lo general a una especialización del producto en un área, un problema en particular, mientras que las marcaciones externas de la contratapa intentan ampliar las referencias a un público genérico. Existen tantos libros como preguntas que los creyentes formulan a su religión y a quienes la representan institucionalmente.

Por su parte, las marcaciones internas de un texto tienen que ver, en primera instancia, con el género discursivo simple o complejo en el que se encuentra escrito: testimonios, biografias, estudios bíblicos, documentos eclesiásticos, manuales de catequesis, oraciones, novelas, cuentos y comics religiosos, cartas, etc. Como plantea Mijail Bajtin (2002: 248), los usos de la lengua obedecen a diferentes esferas de la actividad humana, las cuales elaboran tipos estables de enunciados, con su estilo y reglas de composición. La esfera religiosa cuenta con un amplio repertorio de géneros que las casas editoriales promueven o relegan según los principios de clasificación que prioricen. A su vez, las marcas o señales internas remiten a otros autores que avalan, discuten, amplían, critican o refuerzan los argumentos del libro, lo que delimita un espacio de presencias y ausencias que rigen la polifonía del texto.

Veamos dos ejemplos de marcaciones: el documento eclesiástico de instrucción pastoral sobre los medios de comunicación social Communio et Progressio, editado por Paulinas, y el libro de Bernardo Stamateas, ${ }^{4}$ Intoxicados por la fe, de editorial Grijalbo. El primero se caracteriza por ser una publicación casi completamente despojada de marcas comerciales, un material de difusión y de bajo costo más pequeño que un libro, con una encuadernación sencilla, de tapa blanda azul claro, con el nombre del documento en el centro y la referencia a la Pontificia Comisión para los Medios de Comunicación Social en el

4 Bernardo Stamateas es sexólogo clínico y pastor de la iglesia bautista Presencia de Dios, en Buenos Aires, Argentina. Se desempeña a su vez como escritor y conferencista en el área de espiritualidad. Durante los últimos años ha publicado numerosos libros y muchos de ellos -es el caso de Gente tóxica - se han transformado en best sellers locales. Stamateas participa de manera recurrente en programas de televisión y radio, que lo acercan al gran público. 
borde superior. Sin referencias, recomendaciones o estudios preliminares, el libro comienza por una breve reseña sobre la génesis del documento y los distintos esquemas, con sus respectivas reuniones, que llevaron a la aprobación final del mismo por parte del Santo Padre en 1971. El estilo, al igual que la composición de la escritura, es claro, analítico e impersonal, como un texto académico construido en diálogo con otros documentos similares. Dividido en tres partes, el texto versa sobre los principios doctrinales que deben regir el uso correcto de los medios de comunicación social - la prensa, el cine, la radio, la televisión y el teatro- desde un punto de vista cristiano. Se los evalúa en sus distintas partes como factores del progreso humano y se define a continuación el quehacer de los católicos, sus exigencias y responsabilidades frente a los avances de la técnica. No es un análisis de contenidos, sino de marcas. Y según las reglas del género, el documento eclesiástico plantea un diálogo de coherencia interna con un discurso de institución. Por eso las referencias remiten en su mayoría a encíclicas, ${ }^{5}$ alocuciones y discursos papales sobre el tema. Communio et Progressio es un bien de cultura con marcaciones fuertes, religiosamente definidas, que apuntan a construir un discurso católico de institución con base en principios de doctrina dirigidos a un circuito restringido de consumidores, vinculados fuertemente al núcleo duro y a los cuadros medios. Se imponen principios sacerdotales de pureza, erudición y estudio de la Palabra, propios del vector espiritual.

En el extremo opuesto, el libro de Stamateas es un ejemplo de marcaciones débiles o lavadas en términos religiosos. Las marcas externas corresponden a las orientaciones comerciales. Por ejemplo, el nombre del autor por ser conocido en el borde superior, con una referencia a éxitos previos - "Autor de los best sellers Gente tóxica y Autoboicot"-, luego el título - Intoxicados por la fe. Cómo ser libres de una religión tóxica y vivir una espiritualidad feliz-, el logo de la editorial y un sello — "Nuevo libro"- que evita confusiones con títulos similares. La solapa anterior presenta una foto sonriente y de medio cuerpo de Stamateas. De acuerdo con una pauta o modo situacional de presentación de sí, el texto describe al autor primero como licenciado en psicología, sexólogo, clínico, escritor, conferencista —en ese orden-, y por último como pastor del ministerio Presencia de Dios. La cadena de referencia se extiende en la solapa posterior, en la que se mencionan otros títulos de la colección que pueden interesar a un perfil similar de lector: libros de Osho, ChinNing Chu, Sergio Marquet y Alejandra Stamateas. Las marcaciones apuntan con fuerza a una espiritualidad abierta, no confesional, indefinida. El espíritu de las citas de la contratapa opera en la misma dirección. Allí aparecen fragmentos seleccionados de figuras de la cultura, cada una presentada con todos los títulos posibles, que recomiendan el libro: el escritor, historiador y médico Pacho O’Donell, el filósofo y escritor Alejandro Rozitchner, el sacerdote Luis Farinello y el rabino Sergio Bergman. Las credenciales o el carisma de personas consagradas gracias a su elevada exposición trazan un marco de referencia simbólico para el libro, un preámbulo de corte ecuménico. La apuesta de fondo consiste en desmarcar el producto de etiquetas fuertes o por el contrario multiplicar las formas de etiquetamiento dentro del amplio mundo de la espiritualidad. Internamente las marcas obedecen a una combinación de géneros discursivos vinculadas a la autoayuda cristiana y a la psicología. El autor se propone identificar "actitudes y conductas que, con la excusa de la fe, enferman nuestra vida diaria" (Stamateas, 2010: 14). Con estructuras similares, aunque no idénticas, cada capítulo reconoce una actitud tóxica —implícitamente

5

Sobre todo y por ser la primera en fijar una posición en torno a los medios de comunicación masiva, Inter Mirifica, aunque también se citan otras encíclicas, como Mater et Magistra, Guardium et Spes, Dignitatis Humanae. 
asociada a confesiones identificables-, se las describe, ordena y caracteriza a partir de etapas y perfiles construidos desde anécdotas, fragmentos de entrevistas y la misma experiencia profesional del autor. El ordenamiento de la conducta nociva, patológica, permite explicitar su estructura y desarmarla. Para ello se proponen relecturas de la Biblia combinadas con nociones refiguradas del psicoanálisis y ejercicios personales - test para saber si somos neuróticos, perfeccionistas, etc.- - Los capítulos terminan con un resumen sobre la alternativa de la "fe sana" en relación con el problema planteado. El estilo de escritura es cálido, familiar, no recurre a la lógica del testimonio de conversión y conserva una distancia profesional en el trabajo analítico de reconocer actitudes y conductas tóxicas. El libro concluye con una bibliografía orientada a temas de psicología y religión. Sin embargo, las marcas dominantes del texto corresponden a frases puntuales de personalidades destacadas de la cultura universal que refuerzan, sintetizan o amplían el argumento de Stamateas en cada capítulo. Conviven Víctor $\mathrm{Hu}-$ go, Paulo Coelho, Confucio, Aristóteles, Beethoven, John Stuart-Mill, San Martín, Michael Jordan, Goethe, Isaac Asimov, José Ingenieros, Calderón de la Barca, Chesterton, Gandhi, Ortega y Gasset, Lutero y la Biblia, por nombrar algunos. Ellos constituyen las marcaciones ampliadas que confluyen a lo largo del libro y habilitan un sistema extendido de referencia en el que la espiritualidad, siempre de raigambre judeo-cristiana, renuncia a las identidades particulares y se universaliza. Se trata de un objeto de cultura que por sus marcas y estética se dirige a los estilos periféricos de consumo. Por eso no es extraño que incluso editoriales evangélicas regidas por el vector comercial caractericen la saga tóxica de Stamateas como una forma de "Evangelio light". El ordenamiento que ofrecen sus marcaciones puede parecer ecléctico o lavado para una literatura de iglesia, pero es probable —en palabras de Pablo Semán (2006: 116-120)— que estos criterios amplios se adecúen mejor al modo en que los mismos lectores organizan sus bibliotecas con base en la recomposición de las categorías a partir de las cuales agrupan autores o temas a simple vista contradictorios.

En ambos casos, el de las marcaciones fuertes del documento eclesiástico y las débiles de la autoayuda, se produce un efecto de sobredeterminación. ${ }^{6}$ Las formaciones significativas tienden a ramificarse y generan un exceso de sentido. Lo mismo ocurre con las interpretaciones que habilitan distintos niveles de lectura, pero en direcciones opuestas. En el primer caso las marcas fuertes sobredeterminan un discurso de institución que representa la voz oficial de la Iglesia católica sobre principios de doctrina en los que se fija una postura orientada a producir una imagen de coherencia y continuidad con las comunicaciones previas: las encíclicas, los discursos y las alocuciones papales. En el segundo, las marcas débiles sobredeterminan la composición del producto, con base en una estrategia de desmarcación resultado del sobreetiquetamiento. La intención subyacente apunta a alivianar las definiciones estrictas, desdibuja las fronteras y los modos periféricos de abordar el libro.

\section{Conclusiones}

La captación sociológica de las mercancías religiosas supone estudiar el entramado de relaciones que las hace existir. Por ello fue preciso atender a la "pre-historia" de los objetos culturales, esto es, a las unidades productivas que los diseñan, modelan y fabrican de acuerdo con una visión en algunos casos de iglesia-empresa y en otros sólo de empresa que le da forma a una política cultural de bienes religiosamente marcados. Éste fue el objetivo principal

$6 \quad$ En una acepción más cercana a las primeras formulaciones del psicoanálisis que a los usos althusserianos del término. 
de nuestro artículo, la pre-historia de un modelo peculiar de mercancías, vistas a través de sus productores más importantes: las editoriales.

Intentamos dilucidar el nudo de relaciones sociales que cristalizan en el objeto-libro y sus agentes de producción. Analizamos las principales casas editoriales argentinas, sobre todo del medio católico y evangélico, a partir de entrevistas en profundidad. De allí emergieron dos orientaciones productivas que tensionan internamente la industria editorial. Por un lado, el vector espiritual que produce materiales de formación, dirigidos fundamentalmente a iniciados o especialistas. Esta orientación suele coincidir con empresas administradas por religiosos que se apoyan financieramente en donaciones y subsidios de su comunidad, su iglesia o agencias externas. Los objetos de cultura hacen foco en la pureza de la Palabra, la correcta interpretación, y apuestan de manera simultánea a la catequesis y a un pequeño mercado especializado. Por otro lado, el vector comercial fabrica materiales de espiritualidad para el gran público. Aquí predominan las empresas laicas, de familia, que dependen sólo de las ventas para subsistir. Por eso su estrategia apunta a la importación de best sellers extranjeros y a la publicación de referentes locales. El énfasis teológico recae sobre la experiencia de lo sagrado, vale decir, las vivencias individuales trasmitidas en las narrativas del testimonio. Las orientaciones económicas se ajustan, a su vez, a una clasificación de la demanda que distingue a los creyentes-consumidores según el grado de pertenencia institucional. La propuesta de renombrar los perfiles con los términos de núcleo duro, cuadros medios, periferia y marginales obedece al intento de distinguir maneras de relacionarse con la religión y su cultura material. Por último, fueron exploradas las marcaciones fuertes y débiles que componen el documento eclesiástico Communio et Progressio y el libro de Bernardo Stamateas, Intoxicados por la fe, con el objeto de analizar por medio de casos concretos el sistema de marcas que le otorga identidad a los productos culturales.

Para concluir, es importante señalar que el editor es un seleccionador de pautas religiosas — de tópicos, discursos, modelos de conducta, lecciones, testimonios, etc. - a las que se les otorga un rango privilegiado de visibilidad y acceso. Ellas existen como objetos dentro de la cultura material con la que un grupo humano se define a sí mismo. Este mundo de cosas, de mercancías culturales, se encuentra habitado por bienes que proponen un cierto ordenamiento de la experiencia - llamémosla aurática - de la religión, es decir, de las sensaciones que se desprenden de la vivencia de lo numinoso. Y ésta, al igual que las obras de arte en el argumento clásico de Walter Benjamin (1989: 18-23), logra emanciparse de su ritual de origen — del culto, la imposición de manos, el sacramento, la alabanza o la adoración- a través de la reproductibilidad técnica que habilitan las editoriales. Las mercancías religiosas permiten, en más de un sentido, recrear la autenticidad de esta experiencia, pero emancipada de su contexto de emergencia, de sus ritos y vivencias colectivas. D

\section{Bibliografía}

Algranti, Joaquín, 2011, "La religión como cultura material. Socio-génesis de los circuitos editoriales en el mundo católico y evangélico", en Horizontes Antropológicos, año 17, núm. 36, pp. 67-93.

Bajtin, Mijail, 2002, "El problema de los géneros discursivos”, en Mijail Bajtin, Estética de la creación verbal, Siglo XXI, México.

Belchior Mesquita, Wania Amélia, 2007, “Um pé no reino e outro no mundo: consumo e lazer entre pentecostais”, en Horizontes Antropológicos, año 13, núm. 28, pp. 117-144.

Benjamin, Walter, 1989, “La obra de arte en la época de la reproductibilidad técnica”, en Walter Benjamin, Discursos interrumpidos I, Taurus, Buenos Aires, pp. 17-57. 
Bourdieu, Pierre, 2003, Creencia artística y bienes simbólicos. Elementos para una sociología de la cultura, Aurelia Rivera, Córdoba.

Canavire, Vanina Belén, 2013, "Escenas de lectura e industria cultural: el caso de los libros de autoayuda”, en Comunicación y Sociedad, núm. 19, pp. 41-60.

Catoggio, Soledad, Gabriela Irrazábal y Verónica López Tessore, 2013, "Las prácticas y creencias religiosas de los habitantes de la Argentina según la asistencia al culto", en Fortunato Mallimaci (dir.), Atlas de la religión en la Argentina, Biblos, Buenos Aires, pp. 180-188.

Douglas, Mary y Baron Isherwood, 1990, El mundo de los bienes. Hacia una antropología del consumo, Grijalbo, México.

Garma Navarro, Carlos, 2000, "Del himnario a la industria de la alabanza. Un estudio sobre la transformación de la música religiosa", en Ciencias Sociales y Religión, año 2, núm. 2, pp. 63-85.

James, William, 1994, "La realidad de lo no visible”, en William James, Las variedades de la experiencia religiosa. Estudio de la naturaleza humana, Planeta-Agostini, Barcelona, pp. 51-69.

Lewgoy, Bernardo, 2004, "O libro religioso no Brasil recente: uma reflexão sobre as estratégias editoriais de espíritas e evangélicos", en Ciencias Sociales y Religión, año 6, núm. 6, pp. 51-69.

Ludueña, Gustavo, 2009, "Performance y popularización de una vertiente del espiritismo argentino”, en Debates do NER, vol. 2, núm. 15, pp. 71-103.

Mallimaci, Fortunato, 2009, "Cuentapropismo religioso: creer sin ataduras. El nuevo mapa religioso en la Argentina urbana", en Aldo Ameigeiras y José Pablo Martín (eds.), Religión, política y sociedad. Pujas y transformaciones en la historia argentina reciente, Prometeo, Universidad Nacional de General Sarmiento, Buenos Aires, pp. 15-45.

Martinoff, Eliane da Silva, 2010, “A música evangélica na atualidade: algumas reflexões sobre a relação entre religião, mídia e sociedades”, en Revista da Abem, núm. 23, pp. 67-74.

Meyer, Brigit, 2006, "Impossible Representations: Pentecostalism, Vision and Video Technology in Ghana”, en Brigit Meyer y Annelies Moors (eds.), Religion, Media, and the Public Sphere, Indiana University Press, Bloomington, pp. 290-312.

Morin, Edgar, 1964, Las estrellas del cine, Eudeba, Buenos Aires.

Semán, Pablo, 2006, “Entre pentecostés y Babel. El caso de Paulo Coelho y sus lectores”, en Pablo Semán, Bajo continuo. Exploraciones descentradas sobre cultura popular y masiva, Gorla, Buenos Aires, pp. 111-136.

Setton, Damián y Joaquín Algranti, 2009, "Habitar las instituciones religiosas: corporeidad y espacio en el campo judaico y pentecostal en Buenos Aires”, en Alteridades, vol. 19, núm. 38, pp. 77-94.

Silveira Campos, Leonildo, 2012, "Bíblias no mercado: o poder dos consumidores e a competição entre os editores. O caso da sociedade bíblica do Brasil”, en Revista de Estudos da Religião, vol. 12, núm. 2, pp. 35-61.

Stamateas, Bernardo, 2010, Intoxicados por la fe, Grijalbo, Buenos Aires.

Torre, Renée de la, 2006, "Circuitos mass mediáticos de la oferta neoesotérica: new age y neomagia popular en Guadalajara”, en Alteridades, año 16, núm. 32, pp. 29-41.

2008, “La imagen, el cuerpo y las mercancías en los procesos de translocalización religiosa en la era global”, en Ciencias Sociales y Religión, año 10, núm. 10, pp. 49-72.

— y Cristina Gutiérrez Zúñiga, 2005, "La lógica del mercado y la lógica de la creencia en la creación de mercancías simbólicas", en Desacatos. Revista de Antropología Social, núm. 18, pp. 53-70.

Volóshinov, Valentín, 2009, “El estudio de las ideologías y la filosofía del lenguaje”, en Valentín Volóshinov, El marxismo y la filosofía del lenguaje, Godot, Buenos Aires, pp. 27-39.

Wright, Pablo y María Cristina Messineo, 2013, "La producción cultural del imaginario esotérico. Una visita desde Buenos Aires", en Cultura y Religión. Revista de Sociedades en Transición, vol. 7, núm. 1, pp. 30-41.

Yúdice, George, 2008, “La globalización de América Latina: Miami”, en George Yúdice, El recurso de la cultura. Usos de la cultura en la era global, Gedisa, Barcelona, pp. 235-250. 